\title{
RELAÇÕES SOLO-GEOAMBIENTE EM ÁREAS DE OCORRÊNCIA DE IPUCAS NA PLANÍCIE DO MÉDIO ARAGUAIA - ESTADO DE TOCANTINS ${ }^{1}$
}

\author{
Alan Kardec Elias Martins², Carlos Ernesto G. R. Schaefer ${ }^{3}$, Elias Silva ${ }^{4}$, Vicente Paulo Soares ${ }^{4}$, Guilherme \\ Resende Corrêa ${ }^{5}$ e Bruno Araújo Furtado de Mendonça ${ }^{5}$
}

\begin{abstract}
RESUMO - Dentre as paisagens do médio rio Araguaia, destacam-se as extensas planícies e depressões sazonalmente alagadas. Nelas se inserem formações florestais higrófilas denominadas Ipucas, como enclaves peculiares pela sua fitossociologia e ambiente pedogeomorfológico. Esses fragmentos florestais naturais ocorrem na planície fluvial, em região de ecótono entre o Cerrado e a Floresta Amazônica. Neste estudo, foi selecionada uma área de 8.200 ha, situada no Município de Lagoa da Confusão, TO, sendo caracterizados nove perfis de solos em diferentes pedoambientes e suas inter-relações nas paisagens da planície do Araguaia, com ênfase nas áreas de Ipucas. Os pedoambientes apresentam grande diversidade, com amplo domínio de solos gleizados, pobres em nutrientes e com plintita em subsuperfície, com teores variáveis de carbono orgânico. Excetuando as áreas de calcário aflorante na borda elevada da planície, onde predominam Cambissolos Háplicos eutróficos com acentuada riqueza química, os solos predominantes no interior da planície do Médio Araguaia, dominantemente Plintossolos e Gleissolos, são acentuadamente pobres em nutrientes e ácidos, mesmo sob formações florestais de Ipucas. Nessas últimas, há um acúmulo de matéria orgânica pelo ambiente hidromórfico redutor e ácido. Por serem áreas extremamente frágeis a intervenções antrópicas, e pouco interligadas, as Ipucas devem ser consideradas áreas de preservação permanente, sendo estreitamente ligadas ao ciclo hidrológico da planície do Araguaia.
\end{abstract}

Palavras-chave: Ecologia de paisagem, pedoambientes, planície fluviolacustre, fragmentos florestais, ecótono, Plintossolos e Gleissolos.

\section{SOIL-GEOENVIRONMENT RELATIONSHIPS IN THE IPUCAS REGION OF THE MID-ARAGUAIA FLOODPLAIN, TOCANTINS STATE, SOUTHERN AMAZONIA}

\begin{abstract}
Amongst the landscape features of Mid Araguaia river valley, there are vast coalesced floodplains and waterlogging depressions, all seasonally inundated. There, scattered forest fragments are found, being regionally called 'Ipucas', with peculiar floristic and geomorphic features. These forest fragments are elements of the natural transition zone (ecotone) between Amazonia Forest and Cerrado. We selected an area of approximately 8.200 ha in the municipality of 'Lagoa da Confusão', for detailed studies of nine soil profiles. All pedoenvironments were characterized, with emphasis on the Ipucas and their ecological relationships. There is a dominance
\end{abstract}

\footnotetext{
${ }^{1}$ Recebido em 28.04.2004 e aceito para publicação em 10.11.2005.

${ }^{2}$ Fundação Universidade do Tocantins - UNITINS.

${ }^{3}$ Departamento de Solos e Nutrição de Plantas da Universidade Federal de Viçosa - UFV.

${ }^{4}$ Departamento de Engenharia Florestal da UFV. E-mail: <eshamir@ufv.br>.

${ }^{5}$ Programa de Pós-Graduação em Solos e Nutrição de Plantas da UFV.
} 
of nutrient-depleted soils, most with gleying and plinthite, with varying amounts of organic carbon. Except for the Eutrophic Haplic Cambisols on calcareous substrate from the elevated border, all soils from the floodplain (Dystrophic Plinthosols and Gleysols) are acid and nutrient-poor, even under 'Ipucas'forest formation. In the Ipucas, organic matter accumulates due to acid-reducing condition, being extremely fragile to human intervention. For this reason, and considering the low degree of connection between forest fragments, Ipucas should be considered as permanent protected areas, being closely related to the overall hydrological cycle of the Araguaia floodplain.

Keywords: Landscape ecology, pedoenvironment, floodplain ecology, forest fragments, ecotones, Plinthosols and Gleysols.

\section{INTRODUÇÃO}

As Ipucas constituem uma das mais interessantes e peculiares paisagens da Depressão do Médio Araguaia, sendo constituídas por fragmentos florestais descontínuos, como ilhas de florestas de ocorrência natural, em meio aos varjões sujo e limpo (campo sujo e campo limpo). Essas últimas formações predominantemente campestres são naturalmente interrompidas pelo aparecimento dessas formações florestais naturais. As Ipucas possuem características fitofisionômicas semelhantes às dos ambientes florestais inundáveis da Amazônia. São formações identificadas como "Florestas Estacionais Semideciduais Aluviais" e ocupam as acumulações fluviais quaternárias, sendo a sua estrutura fisionômica semelhante à da floresta de galeria, da qual diferem apenas floristicamente. Possuem uma estrutura densa, em geral com dois estratos de vegetação, sendo as árvores de maior freqüência e porte o Calophyllum brasiliense (landi) e Vochysia sp. (canjerana) (BRASIL, 1981; MARTINS et al., 2002). Localizam-se em meio a extensas planícies, periodicamente inundadas pelas cheias dos rios que drenam a depressão do Araguaia. Constitui essa planície uma vasta superfície rebaixada, com altimetria que varia de 180 a 220 m, drenada pela Bacia do Araguaia, com influência da Bacia do Xingu na parte noroeste, através da atuação de vários de seus afluentes (BRASIL, 1981). Regionalmente, situa-se entre o Planalto do Interflúvio Araguaia-Tocantins, os Patamares do Interflúvio Araguaia-Tocantins e o rio Araguaia (BRASIL, 1981).

Do ponto de vista ecológico, as Ipucas são florestas de natureza aluvial, sob um regime climático estacional de cinco a seis meses secos. As Ipucas são elementos importantes na drenagem regional da planície, uma vez que no período de cheias estabelecem a ligação entre os vários rios, córregos e lagoas. A precipitação média

R. Árvore, Viçosa-MG, v.30, n.2, p.297-310, 2006 anual da região estudada é de $1.750 \mathrm{~mm}$, concentrada entre os meses de outubro a abril. A temperatura média é de $24^{\circ} \mathrm{C}$, e a da umidade relativa do ar permanece em torno de 80 a $85 \%$ ao longo do ano (BRASIL, 1994). A atuação do gradiente climático - chuva e seca torna sazonal a deposição e a mineralização da matéria orgânica, elemento fundamental na ciclagem dos nutrientes dos ecossistemas de planície. No final da estiagem, os solos hidromórficos sob Ipucas estão ressecados, com camadas de 20 a $30 \mathrm{~cm}$ de folhas secas. No período chuvoso, a atividade microbiana é restrita pela inundação, favorecendo o acúmulo de matéria orgânica em superfície.

A planície do Araguaia apresenta aspectos característicos, como topografia plana e baixa altitude, nível do lençol freático superficial elevado, predominância de Plintossolos e Gleissolos, ambos com impedimento de drenagem e periodicidade de inundação. Atuando em conjunto e por um período prolongado de estiagem, essas particularidades proporcionam ao ambiente o desenvolvimento de formas biológicas próprias, em nível microclimático (BRASIL, 1994). Por tratar-se de uma área inteiramente dependente da inundação, a forma de relevo atua como elemento fundamental no processo seletivo e na fixação da vegetação. Para grande número de plantas, quanto maior for o encharcamento do solo, mais impróprio torna-se o ambiente, ocorrendo, dessa forma, uma substituição de indivíduos arbóreos por elementos herbáceos, que se propagam de pontos mais altos (melhor drenagem) para áreas mais baixas (pior drenagem).

Apesar da importância ecológica do vasto ambiente hidromórfico sazonal da Depressão do Médio Araguaia, o avanço da fronteira agrícola na região, em razão da abundância de água e do relevo plano, favorável à mecanização, ameaça a conservação desses importantes 
fragmentos florestais. A carência de estudos sobre sua formação e relações ecológicas aí existentes, especialmente no que tange aos solos, ressalta a necessidade de um melhor entendimento dessas formações em seu estado natural, tendo em vista que a contínua incorporação dessas áreas ao processo produtivo mecanizado vem reduzindo drasticamente as Ipucas.

A planície do Araguaia é uma área com características ambientais singulares entre os ambientes de terras alagáveis. Poucos estudos gerais sobre os solos desse ambiente podem ser encontrados na literatura. Segundo Codetins (1996), dominam Neossolos Flúvicos, Plintossolos e Latossolos Amarelos Plínticos, originados de materiais pleistocênicos de natureza argilo-arenosa, geralmente rasos e pobres. Ona (2001), estudando em caráter geral seqüências de solos na área, observou que estes exibiram elevada acidez, baixa capacidade de troca de cátions e carência de nutrientes, identificando as classes: Latossolo Amarelo distrófico plíntico, Argissolo Vermelho-Amarelo e Plintossolos.

Neste trabalho, objetivou-se uma caracterização físico-química detalhada dos solos sob Ipucas e do seu entorno, para subsidiar o conhecimento ecológico de sua ocorrência. Foi selecionada uma área representativa e bem conservada, no Município de Lagoa da Confusão, no Estado de Tocantins.

\section{MATERIAL E MÉTODOS}

\section{1. Área de estudo}

A área de estudo se insere na planície do Araguaia e em sua borda, no Município de Lagoa da Confusão, nas proximidades da Ilha do Bananal, Estado do Tocantins, situada entre as latitudes $10^{\circ} 40^{\prime}$ e $10^{\circ} 57^{\prime}$ sul e longitudes $49^{\circ} 30^{\prime}$ a $49^{\circ} 50^{\prime}$ oeste.

O predomínio de áreas alagáveis favorece formações herbáceas, principalmente gramíneas, inibindo a dispersão de elementos arbóreos. Esse relacionamento é retratado na predominância de formações campestres, em toda a área de inundação do Araguaia (BRASIL, 1994).

\subsection{Solos}

Os solos foram mapeados a partir de cartas planialtimétricas, fotografias aéreas e imagens de satélites. Abriram-se trincheiras em número suficiente para representar a diversidade dos geoambientes associados à área do estudo, e realizou-se a coleta de amostras de solo para análises químicas e físicas.

Nove perfis de solos foram selecionados, desde a borda até a planície, descritos morfologicamente e amostrados em toposseqüência. O material coletado, após transporte para o laboratório, foi secado ao ar, destorroado e passado em peneira de duas malhas de $2 \mathrm{~mm}$, para obtenção da terra fina secada ao ar (TFSA).

Os perfis amostrados foram classificados segundo o Sistema Brasileiro de Classificação de Solos (5 Aproximação), de acordo com os critérios morfológicos e as características químicas, físicas e mineralógicas (EMBRAPA, 1999). A cor do solo foi determinada em amostras de terra fina secada ao ar, utilizando a caderneta de Münsell (MÜNSELL, 1994).

A composição granulométrica foi determinada após dispersão da TFSA com $\mathrm{NaOH} 1 \mathrm{~mol} \mathrm{~L}^{-1}$ e agitação; a fração areia foi obtida por peneiramento úmido; a argila, pelo método de Bouyoucus; e o silte, por diferença (EMBRAPA, 1999).

Na caracterização química, determinou-se o pH em água, e o $\mathrm{pH}$ em $\mathrm{KCl}\left(1 \mathrm{~mol} \mathrm{~L}^{-1}\right)$ foi determinado potenciometricamente na suspensão solo-solução de 1:2,5, com tempo de contato mínimo de uma hora e agitação da suspensão antes da leitura; o cálcio e o magnésio trocáveis foram extraídos com $\mathrm{KCl} 1 \mathrm{~mol} \mathrm{~L}^{-1}$, na proporção de 1:20, e dosados por absorção atômica; o potássio e

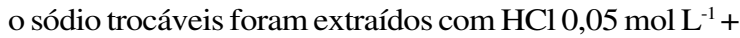
$\mathrm{H}_{2} \mathrm{SO}_{4} 0,025 \mathrm{~mol} \mathrm{~L}^{-1}$, na proporção de 1:10, e dosados por fotometria de chama; o alumínio trocável foi extraído com $\mathrm{KCl} 1 \mathrm{~mol} \mathrm{~L}^{-1}$, na proporção de 1:20, e determinado por titulação com $\mathrm{NaOH} 0,025 \mathrm{~mol} \mathrm{~L}^{-1}$; a acidez extraível $\left(\mathrm{H}^{+}+\mathrm{Al}^{3+}\right)$ foi obtida com solução de acetato de cálcio $1 \mathrm{~N}$ ajustada a $\mathrm{pH} 7,0$, na proporção de $1: 15$, e determinada por titulação com $\mathrm{NaOH} 0,0606 \mathrm{~mol} \mathrm{~L}^{-1}$; o fósforo disponível foi extraído com solução de $\mathrm{HCl} 0,05 \mathrm{~mol} \mathrm{~L}^{-1} \mathrm{e} \mathrm{H}_{2} \mathrm{SO}_{4} 0,025$ mol L ${ }^{-1}$ (Mehlich-1) e determinado por colorimetria na presença de ácido ascórbico; e o carbono orgânico foi extraído pelo método volumétrico com bicromato de potássio e por titulação com sulfato ferroso (EMBRAPA, 1999).

\section{RESULTADOS E DISCUSSÃO}

Os solos analisados apresentam-se ácidos com valores de $\mathrm{pH}$, no horizonte A, variando entre 4,1 e 6,8 . Valores de $\mathrm{pH}$ superiores a 5,5 foram encontrados em perfil sob influência de rochas calcárias $\mathrm{P} 1$ e P2.

R. Árvore, Viçosa-MG, v.30, n.2, p.297-310, 2006 
Os valores de alumínio trocável $\left(\mathrm{Al}^{3+}\right)$ foram maiores nos solos sob Ipucas, com valores de $\mathrm{Al}^{3+}$ crescente da borda para o centro. Em P1 e P2, os solos mostraram valores de $\mathrm{Al}^{3+}$ nulos, além de teores de $\mathrm{Ca}^{2+}$ elevados, por tratar-se de solo sob influência de calcário (P1) ou laterítica $(\mathrm{P} 2)$. Valores de $\mathrm{pH}$ na faixa compreendida entre 4,1 e 5,5 parecem representar as condições gerais de acidez dos solos da planície do Araguaia, conforme verificado em outros estudos de solos na região (CODETINS, 1996; ONA, 2001), corroborando o resultado do presente estudo.

A textura nos Plintossolos variou no horizonte A, de franco-arenosa $\left(660 \mathrm{~g} \mathrm{~kg}^{-1}\right.$ de areia e $130 \mathrm{~g} \mathrm{~kg}^{-1} \mathrm{de}$ argila) a franco-argilo-arenosa $\left(570 \mathrm{~g} \mathrm{~kg}^{-1} \mathrm{de}\right.$ areia e $270 \mathrm{~g} \mathrm{~kg}^{-1}$ de argila), enquanto em subsuperfície (Bf ou Cf) variou de franco-arenosa $\left(810 \mathrm{~g} \mathrm{~kg}^{-1} \mathrm{de}\right.$ areia e $130 \mathrm{~g} \mathrm{~kg}^{-1}$ de argila) a argilo-arenosa $\left(470 \mathrm{~g} \mathrm{~kg}^{-1} \mathrm{de}\right.$ areia e $410 \mathrm{~g} \mathrm{~kg}^{-1}$ de argila). As perdas seletivas de argila ocorreram por alternância dos estados de oxidação e redução do ferro, pelo processo denominado "ferrólise" (ANDRADE et al., 1997), associado à destruição por hidrólise ácida da caulinita, com conseqüente concentração residual de grãos arenoquartzosos, especialmente em tamanho de areia grossa (AG). Os teores de areia fina (AF) apresentaram valores pouco variáveis em profundidade, indicando menor papel dos mecanismos erosivos em fluxo laminar no transporte diferencial de $\mathrm{AF}$ em relação a AG, observado em superfície nos perfis (P3) e (P5). Características semelhantes de seleção textural foram reportadas para Plintossolos da planície do Araguaia (CODETINS, 1996). As relações AG/AF observadas em profundidade evidenciaram que as perdas de argilas em suspensão (argila dispersa em água) por acidificação (destruição ácida e ferrólise) são acompanhadas por perda relativa de AF, principalmente por erosão laminar, apenas em alguns casos. Os teores de silte, parte do qual deve representar silte funcional em microagregados e nódulos ou concreções, são de forma geral muito variáveis, tanto em profundidade quanto entre perfis, em virtude da natureza sedimentar dos solos.

As relações silte/argila, igualmente muito variáveis, são mais um reflexo das variações sedimentológicas que pedogenéticas dos solos de planície, excetuando-se P1 e P2.

\subsection{Geoambientes e topossequiência da planície do Araguaia}

Na Figura 1 estão representados de forma esquemática os principais elementos dos solos, relevo e geologia, ao longo do transecto estudado, ilustrando os principais geoambientes observados e os solos amostrados. De modo geral, a pedogênese na planície do Araguaia é marcadamente influenciada pelos regimes hidrológicos (lençol freático e transbordamento do leito de rios). Variações pedológicas associadas a toposseqüências são características em região de ecótono.

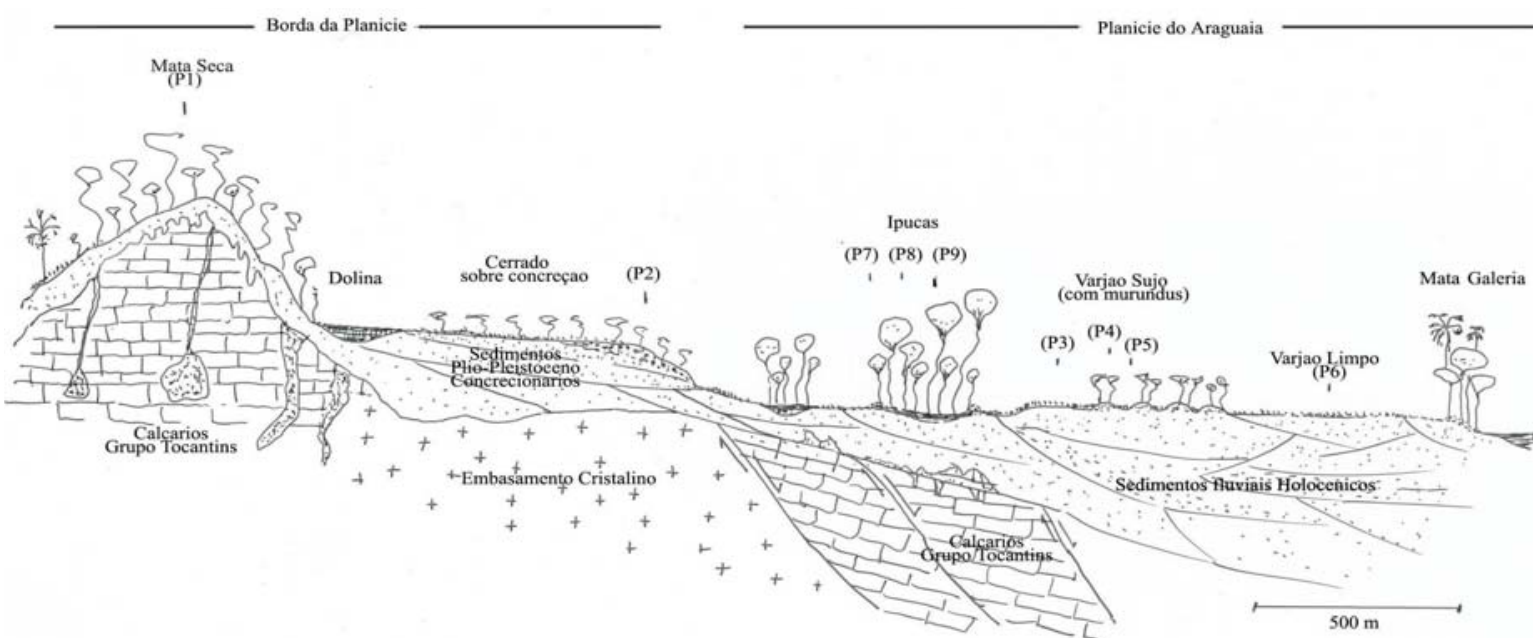

Figura 1 - Toposseqüência da área de estudo, contemplando os aspectos litológicos e os geoambientes. Figure 1 - Toposequence of the study area, comprising lithological and geoenvironmental aspects. 
Os Plintossolos da planície do Araguaia encontramse sob vegetação de Varjões Sujos (com murundus) ou Limpos e são originados de sedimentos recentes do Quaternário. Para seu uso agrícola, as principais limitações são decorrentes da baixa fertilidade natural (distróficos com teor elevado de Al) e má drenagem, pois durante parte do ano ficam saturados de água. Para o uso intensivo desses solos, é necessário o emprego de técnicas de drenagem, além do uso de corretivos e fertilizantes. Entretanto, o uso da vegetação natural como pastejo extensivo é uma alternativa considerada. Quando ocorre o rebaixamento acentuado do lençol freático, a plintita tende a endurecer de maneira irreversível, tornando complicado o manejo do solo.

Os Gleissolos ocorrem em relevo plano e estão sob vegetação predominante de Floresta Aluvial (Ipucas) e Formações Pioneiras. As principais limitações ao uso agrícola decorrem da presença do lençol freático próximo à superfície, do risco de freqüentes inundações e da baixa fertilidade natural. A prática de drenagem é imprescindível para utilização agrícola desses solos. Por questões ambientais, a maior parte dessas áreas deve ser destinada à preservação permanente.

\subsubsection{Pedoambientes de Cambissolos sobre calcários}

O solo P1 foi estudado na área calcária (Figura 1). A amostra foi coletada na cobertura pedogenética sobre afloramento calcário do Grupo Tocantins, constituído por um conjunto de metamorfítos que compõem o Cinturão Araguaia, de idade Pré-Cambriana. Predominam rochas de baixo grau metamórfico, representadas por xistos, filitos, ardósias, metargilitos e metassiltitos, ocorrendo, ainda, rochas vulcânicas básicas serpentinizadas, calcários e mármores.

A vegetação desse ambiente é caracterizada por Mata Seca, em razão de prolongado período de estiagem, de até seis meses. No Brasil central e no Pantanal, ocorrem manchas de Mata Seca (estacional), na região de domínio de Cerrados (RIZZINI, 1992). Na área estudada, essa fitofisionomia se caracteriza pela deciduidade anual do estrato superior, diretamente relacionada com afloramentos de calcário do Grupo Tocantins, estando nas bordas da planície do Araguaia.

As Matas Secas (BRASIL, 1981; RIBEIRO e WALTER, 1998), também denominadas Florestas Estacionais Deciduais (FELFILI, 2001), podem ocorrer sobre afloramentos de rochas calcárias ou basálticas, que dão origem invariavelmente a solos de elevada fertilidade natural quando rasos (Figura 2).

O horizonte A possui teores médios a altos de $\mathrm{P}$, e teores de carbono elevados, bem como Ca e $\mathrm{Mg}$, pelo efeito da ciclagem sobre material calcário (RIBEIRO et al., 1999), além de apresentar evidência de elevada atividade de argila pela CTC total, mas não possui características de fendilhamento típicos de solos com argila de atividade alta (Quadros 1 e 2).

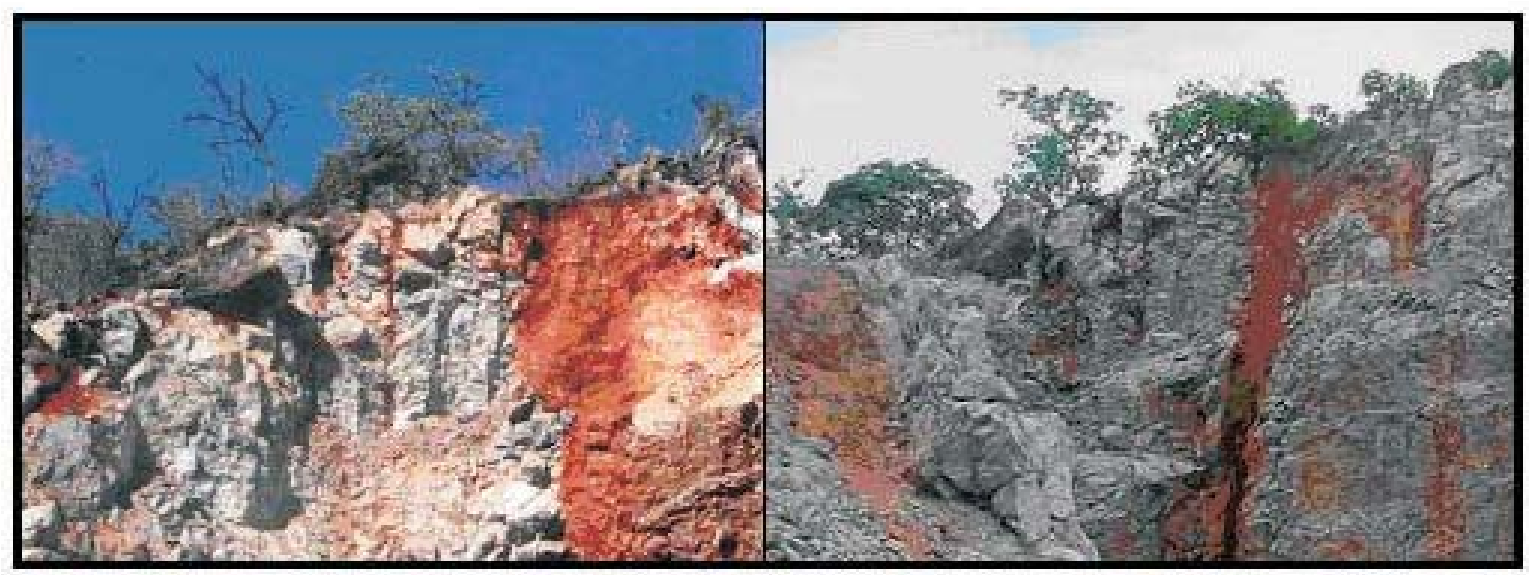

Figura 2 - Borda da planície com presença de rochas calcárias do Grupo Tocantins recobertas por Mata Seca. O local atualmente é usado para extração de calcário.

Figure 2 - Floodplain edges with limestone base rocks of Tocantins Group, covered by Dry Forests. The site is used for limestone extraction. 


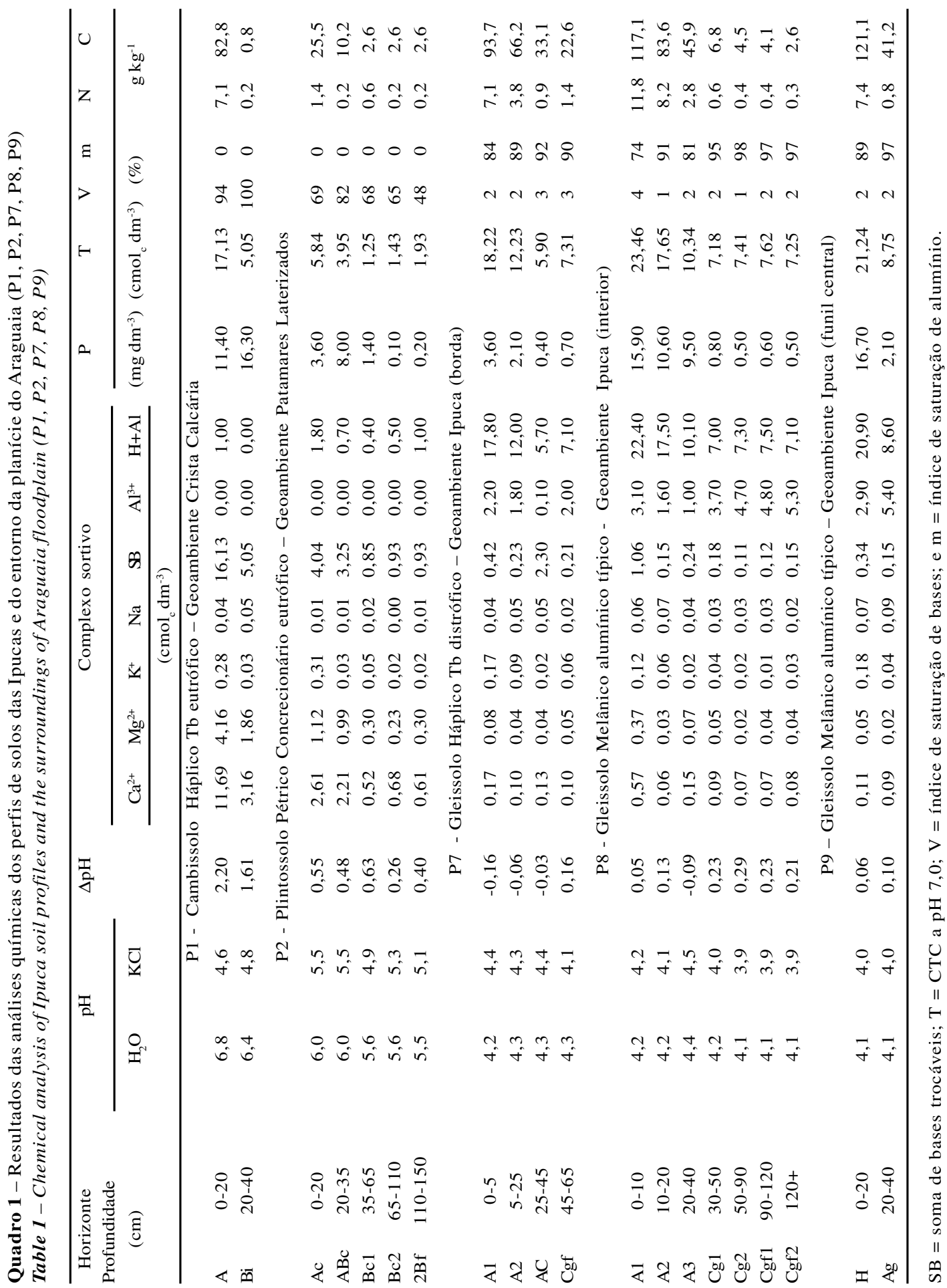




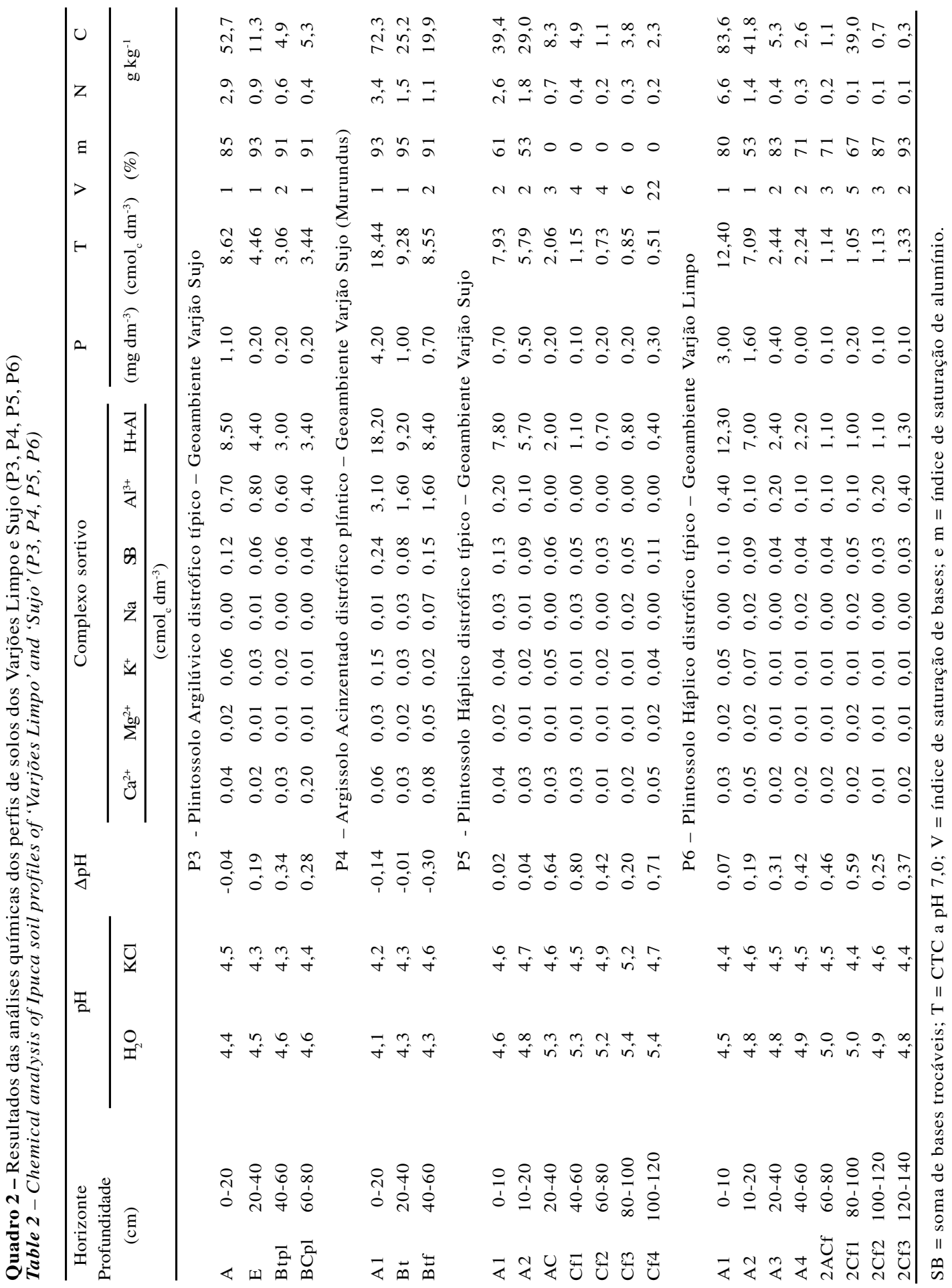

R. Árvore, Viçosa-MG, v.30, n.2, p.297-310, 2006 


\subsubsection{Plintossolo Pétrico sobre cangas lateríticas}

É a classe mais freqüente nas bordas soerguidas da planície do Araguaia. Um perfil típico foi estudado na borda da depressão, em corte de estrada, ligando o Município de Lagoa da Confusão à planície do Araguaia (Quadros 1 e 3). Os cromas da maioria dos horizontes ficaram acima da classe, embora todos os demais aspectos o são (EMBRAPA, 1999). Aárea caracteriza-se por possuir extensa faixa de solos concrecionários, originados do intemperismo de crostas lateríticas, que recobrem indistintamente as unidades geológicas da região. $\mathrm{Na}$ bacia do rio Araguaia, essas crostas ocorrem na forma de platôs descontínuos, geralmente em níveis topográficos mais elevados, em relevo plano a suave ondulado, formando um verdadeiro pavimento na região, não sendo, muitas vezes, representado nos mapeamentos geológicos. Trata-se, portanto, de concreções lateríticas do Pleistoceno, que se apresenta com espessura variável, contendo fragmentos ferruginosos de canga laterítica, ao longo da borda da planície do Araguaia. Representam antigos níveis hidromórficos com plintita convertidos em petroplintita pelo soerguimento, erosão e exposição do material sobrejacente.

A vegetação no perfil é de cerrado stricto sensu, com presença de árvores baixas, inclinadas, tortuosas, com ramificações irregulares e retorcidas, com evidência de queimadas. Os arbustos e subarbustos encontramse espalhados, com algumas espécies apresentando órgãos subterrâneos perenes (xilopódios), que permitem rebrota após a queima ou corte. Os troncos das plantas lenhosas geralmente possuem cascas com cortiça grossa e folhas rígidas e coriáceas, demonstrando o aspecto xeromórfico. Essa fitofisionomia também pode ocorrer em Cambissolos, Neossolos Quartzarênicos, Neossolos Litólicos, Plintossolos ou Gleissolos. No entanto, na borda da planície do Araguaia, boa parte dos cerrados se encontra associada às classes dos Plintossolos Pétricos, Cambissolos ou Latossolos, todos sobre cobertura laterítica, e geralmente concrecionários (BRASIL, 1981). Os teores de nutrientes são baixos, mas bem mais elevados que os solos da planície, apresentando caráter eutrófico em quase todo o perfil.

Quadro 3 - Cor e textura dos perfis de solos das Ipucas e do entorno da planície do Araguaia (P1, P2, P7, P8, P9) Table 3 - Color and texture of soil profiles of 'Ipucas' and the surroundings of Araguaia floodplain (P1, P2, P7, P8, P9)

\begin{tabular}{|c|c|c|c|c|c|c|c|c|}
\hline \multicolumn{2}{|c|}{ Horizonte } & \multirow{2}{*}{$\frac{\text { Cor TFSA }}{\text { Seco }}$} & \multicolumn{5}{|c|}{ Granulometria $\left(\mathrm{g} \mathrm{kg}^{-1}\right)$} & \multirow[t]{2}{*}{ Classe Textural } \\
\hline$\overline{\text { Símbolo }}$ & Profundidade $(\mathrm{cm})$ & & $\mathrm{Ag}$ & Af & $\mathrm{S}$ & Arg & S/Arg & \\
\hline \multicolumn{9}{|c|}{ P1 - Cambissolo Háplico Tb eutrófico - Geoambiente Crista Calcária } \\
\hline A & $0-20$ & $7,5 \mathrm{YR} 3 / 1$ & 290 & 320 & 300 & 90 & 3,33 & Franco-Arenosa \\
\hline $\mathrm{Bi}$ & $20-40$ & $2,5 \mathrm{YR} 4 / 8$ & 380 & 230 & 170 & 220 & 0,77 & Franco-Argilo-Arenosa \\
\hline \multicolumn{9}{|c|}{ P2 - Plintossolo Pétrico Concrecionário eutrófico - Geoambiente Patamares Laterizados } \\
\hline Ac & $0-20$ & $10 Y R 5 / 4$ & 320 & 230 & 270 & 180 & 1,50 & Franco-Arenosa \\
\hline $\mathrm{ABc}$ & $20-35$ & 7,5 YR $6 / 6$ & 360 & 220 & 160 & 260 & 0,61 & Franco-Argilo-Arenosa \\
\hline $\mathrm{Bc} 1$ & $35-65$ & 7,5YR 5/6 & 320 & 220 & 200 & 260 & 0,77 & Franco-Argilo-Arenosa \\
\hline $\mathrm{Bc} 2$ & $65-100$ & $7,5 \mathrm{YR} 6 / 8$ & 380 & 200 & 120 & 300 & 0,40 & Franco-Argilo-Arenosa \\
\hline $2 \mathrm{Bf}$ & $110-150$ & $7,5 \mathrm{YR} 5 / 8$ & 290 & 240 & 140 & 330 & 0,42 & Franco-Argilo-Arenosa \\
\hline \multicolumn{9}{|c|}{ P7 - Gleissolo Háplico Tb distrófico - Geoambiente Ipuca (borda) } \\
\hline A1 & $0-5$ & $7,5 \mathrm{YR} 3 / 1$ & 370 & 210 & 230 & 190 & 1,21 & Franco-Arenosa \\
\hline $\mathrm{A} 2$ & $5-25$ & $7,5 \mathrm{YR} 4 / 1$ & 80 & 250 & 250 & 420 & 0,59 & Argila \\
\hline $\mathrm{AC}$ & $25-45$ & $10 Y R 6 / 2$ & 50 & 250 & 140 & 560 & 0,25 & Argila \\
\hline Cgf & $45-65$ & $10 Y R 6 / 2$ & 50 & 240 & 160 & 550 & 0,29 & Argila \\
\hline \multicolumn{9}{|c|}{ P8 - Gleissolo Melânico alumínico típico - Geoambiente Ipuca (interior) } \\
\hline A1 & $0-10$ & $10 \mathrm{YR} 3 / 2$ & 360 & 130 & 310 & 200 & 1,55 & Franco \\
\hline $\mathrm{A} 2$ & $10-20$ & $10 \mathrm{YR} 3 / 2$ & 260 & 220 & 350 & 170 & 2,06 & Franco \\
\hline A3 & $20-40$ & $10 \mathrm{YR} 5 / 1$ & 100 & 260 & 330 & 310 & 1,06 & Franco-Argilosa \\
\hline $\mathrm{Cg} 1$ & $40-60$ & $2,5 \mathrm{Y} \quad 6 / 2$ & 40 & 340 & 160 & 460 & 0,35 & Argila \\
\hline $\mathrm{Cg} 2$ & $60-90$ & $2,5 \mathrm{Y} \quad 7 / 2$ & 40 & 300 & 180 & 480 & 0,37 & Argila \\
\hline Cgf1 & $90-120$ & $2,5 \mathrm{Y} 7 / 3$ & 30 & 360 & 150 & 460 & 0,33 & Argila \\
\hline Cgf2 & $120-140$ & $2,5 \mathrm{Y} 7 / 3$ & 40 & 370 & 190 & 400 & 0,47 & Argila \\
\hline \multicolumn{9}{|c|}{ P9- Gleissolo Melânico alumínico típico - Geoambiente Ipuca (funil central) } \\
\hline $\mathrm{H}$ & $0-20$ & $10 Y R 3 / 2$ & 180 & 330 & 230 & 260 & 0,88 & Franco-Argilo-Arenosa \\
\hline $\mathrm{Ag}$ & $20-40$ & $2,5 \mathrm{Y} 7 / 3$ & 60 & 270 & 110 & 560 & 0,20 & Argila \\
\hline
\end{tabular}

$\mathrm{Ag}=\operatorname{areia}$ grossa Af $=$ areia fina $\mathrm{S}=$ silte; $\mathrm{Arg}=$ argila; e $\mathrm{S} / \mathrm{Arg}=$ relação silte argila . 


\subsubsection{Plintossolos}

São solos localizados em áreas sazonalmente inundadas, onde a ação biológica da mesofauna tem destaque, formando os Varjões Sujos ou Campos de Murundus (Quadros 2 e 4). O termo Campos de Murundus tem, no Brasil central, o sentido de campos úmidos com "ilhas" ou montes de terra elevada, dominados por extratos arbóreos-arbustívos do cerrado, formando um padrão regular (ARAÚJO NETO et al., 1986), anteriormente classificado como Savana Parque.

A melhor drenagem do solo nos murundus, possibilitada por um microambiente mais aerado, favorece a propagação de espécies arbóreas típicas dos cerrados adjacentes. Os térmitas (cupins) tendem a desempenhar papel importante na formação desses campos (Figura 3) (SILVA JÚNIOR e FELFILI, 1996).

$\mathrm{Na}$ área estudada, os Campos de Murundus localizam-se em regiões de extenso hidromorfismo, formando a planície de inundação, caracterizada por relevo plano. A textura dos solos nos murundus (perfis P4 e P5) varia de franco-argilo-arenosa a argilosa. No período das chuvas, as áreas de vegetação graminosa e herbácea, denominadas Campo Limpo por Ribeiro e Walter (1998), são cobertas por uma lâmina d'água de altura variável, enquanto os murundus permanecem emersos, sendo colonizados por cupinzeiros na parte superior.

Resende et al. (2002) associaram os murundus do Planalto Central às condições de má drenagem. Caracterizam-se por serem formações biogênicas, termíticas, de configuração aparentemente cônica, com dimensões bastante variáveis, em geral da ordem de 3 a 15 m de diâmetro, na base, e uma altura que, raramente, excede $3 \mathrm{~m}$, constituindo agrupamentos específicos, que caracterizam um microrrelevo peculiar. A configuração topográfica que essas formações imprimem à paisagem tem sido mais propriamente denominada microrrelevos de murundus (CORRÊA, 1989).

Quadro 4 - Cor e textura dos solos dos Varjões Limpo e Sujo (P3, P4, P5, P6)

Table 4-Color and texture of soil profiles of 'Varjões Limpo' and 'Sujo' (P3, P4, P5, P6)

\begin{tabular}{|c|c|c|c|c|c|c|c|c|}
\hline \multicolumn{2}{|c|}{ Horizonte } & \multirow{2}{*}{$\frac{\text { Cor TFSA }}{\text { Seco }}$} & \multicolumn{5}{|c|}{ Granulometria $\left(\mathrm{g} \mathrm{kg}^{-1}\right)$} & \multirow[t]{2}{*}{ Classe Textural } \\
\hline Símbolo & Profundidade $(\mathrm{cm})$ & & $\overline{\mathrm{Ag}}$ & Af & $S$ & Arg & S/Arg & \\
\hline \multicolumn{9}{|c|}{ P3 - Plintossolo Argilúvico distrófico típico - Geoambiente Varjão Sujo } \\
\hline A & $0-20$ & $10 Y R 4 / 1$ & 140 & 430 & 210 & 220 & 0,95 & Franco-Argilo-Arenosa \\
\hline $\mathrm{E}$ & $20-40$ & $10 Y R 6 / 3$ & 130 & 370 & 170 & 330 & 0,51 & Franco-Argilo-Arenosa \\
\hline Btf & $40-60$ & $10 Y R 7 / 3$ & 80 & 390 & 120 & 410 & 0,29 & Argilo-Arenosa \\
\hline BCf & $60-80$ & $7,5 \mathrm{YR} 7 / 3$ & 160 & 350 & 140 & 350 & 0,40 & Argilo-Arenosa \\
\hline \multicolumn{9}{|c|}{ P4 - Argissolo Acinzentado distrófico plíntico - Geoambiente Varjão Sujo (Murundus) } \\
\hline A & $0-20$ & $10 Y R 4 / 1$ & 300 & 250 & 180 & 270 & 0,67 & Franco-Argilo-Arenosa \\
\hline $\mathrm{Bt}$ & $20-40$ & $10 \mathrm{YR} 5 / 3$ & 80 & 290 & 180 & 450 & 0,40 & Argila \\
\hline Btf & $40-60$ & $10 Y R 5 / 3$ & 60 & 300 & 200 & 440 & 0,45 & Argila \\
\hline \multicolumn{9}{|c|}{ P5 - Plintossolo Háplico distrófico típico - Geoambiente Varjão Sujo } \\
\hline A1 & $0-10$ & $10 \mathrm{YR} 4 / 2$ & 260 & 270 & 200 & 270 & 0,74 & Franco-Argilo-Arenosa \\
\hline A2 & $10-20$ & $10 \mathrm{YR} 5 / 3$ & 240 & 250 & 240 & 270 & 0,89 & Franco-Argilo-Arenosa \\
\hline $\mathrm{AC}$ & $20-40$ & $2,5 \mathrm{Y} \quad 7 / 4$ & 230 & 270 & 240 & 260 & 0,92 & Franco-Argilo-Arenosa \\
\hline Cf1 & $40-60$ & $2,5 \mathrm{Y} \quad 7 / 4$ & 310 & 250 & 190 & 250 & 0,76 & Franco-Argilo-Arenosa \\
\hline Cf 2 & $60-80$ & $2,5 \mathrm{Y} \quad 7 / 4$ & 330 & 260 & 170 & 240 & 0,71 & Franco-Argilo-Arenosa \\
\hline Cf3 & $80-100$ & 10YR 7/6 & 290 & 260 & 190 & 260 & 0,73 & Franco-Argilo-Arenosa \\
\hline Cf 4 & $100-120$ & $7,5 \mathrm{YR} 7 / 4$ & 270 & 240 & 150 & 340 & 0,44 & Franco-Argilo-Arenosa \\
\hline \multicolumn{9}{|c|}{ P6 - Plintossolo Háplico distrófico típico - Geoambiente Varjão Limpo } \\
\hline A1 & $0-10$ & $10 Y R 3 / 2$ & 300 & 360 & 210 & 130 & 1,61 & Franco-Arenosa \\
\hline A2 & $10-20$ & $7,5 \mathrm{YR} 4 / 1$ & 210 & 380 & 140 & 270 & 0,51 & Franco-Argilo-Arenosa \\
\hline A3 & $20-40$ & $10 Y R 7 / 3$ & 220 & 420 & 130 & 230 & 0,56 & Franco-Argilo-Arenosa \\
\hline A4 & $40-60$ & $10 Y R 7 / 3$ & 260 & 400 & 100 & 240 & 0,42 & Franco-Argilo-Arenosa \\
\hline $2 \mathrm{ACf}$ & $60-80$ & $10 Y R 7 / 3$ & 450 & 310 & 50 & 190 & 0,26 & Franco-Arenosa \\
\hline $2 \mathrm{Cf} 1$ & $80-100$ & $10 Y R \quad 7 / 4$ & 610 & 170 & 50 & 170 & 0,29 & Franco-Arenosa \\
\hline $2 \mathrm{Cf} 2$ & $100-120$ & $10 \mathrm{YR} 7 / 3$ & 610 & 200 & 60 & 130 & 0,46 & Franco-Arenosa \\
\hline $2 \mathrm{Cf} 3$ & $120-140$ & $10 \mathrm{YR} 7 / 3$ & 470 & 320 & 50 & 170 & 0,29 & Franco-Arenosa \\
\hline
\end{tabular}

$\mathrm{Ag}=$ areia grossa; $\mathrm{Af}=$ areia fina $\mathrm{S}=$ silte; $\mathrm{Arg}=\operatorname{argila} ; \mathrm{e} \mathrm{S} / \mathrm{Arg}=$ relação silte argila .

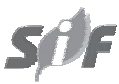

R. Árvore, Viçosa-MG, v.30, n.2, p.297-310, 2006 


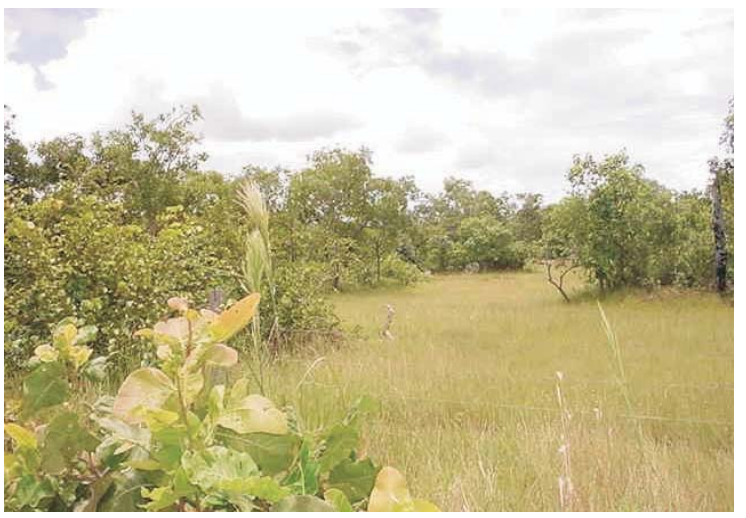

Figura 3 - Área de Campo de Murundus (Varjão Sujo). Nos setores entre murundus predominam gramíneas, e sobre os murundus, local mais bem drenado, ocorrem espécies lenhosas.

Figure 3 - 'Murundus'field ('Varjão Sujo'- small hills). Grasses dominate the sectors between 'murundus'. Over the 'murundus', in well-drained soils, there is occurrence of woody species.

Os solos dos murundus são de baixa fertilidade natural, com teores muito baixos de nutrientes, com Al variável (desde $3,1 \mathrm{cmol}_{\mathrm{c}} \mathrm{dm}^{-3} \mathrm{em} \mathrm{P} 4$ até valores nulos em P5). Os teores de $\mathrm{P}$ são baixos, e o carbono orgânico varia bastante entre os perfis, sendo geralmente elevado na superfície.

O Plintossolo descrito no varjão limpo (P6) possui textura franco arenosa a franco-argila-arenosa, estando associado a Campo Limpo. Nesta vegetação são identificadas diversas espécies da família Poaceae, algumas Cyperaceae, Iridaceae, Eriocaulaceae,
Melastomataceae, Lythraceae, Xyridaceae e Lentibulariaceae, dentre as principais (MARIMOM e LIMA, 2001; CPT, 2002). Eventualmente, verificou-se a ocorrência de plântulas e subarbustos de espécies lenhosas sobre os murundus. As gramíneas mais comuns são as dos gêneros Aristida sp., Panicum sp., Axonopus sp. e Setaria sp. (CPT, 2002).

As formações campestres, em geral, são utilizadas como área de pastoreio extensivo, em razão do denso tapete graminoso. Entretanto, no período das chuvas é necessário o remanejamento dos animais para as áreas mais elevadas do terreno.

O solo é extremamente ácido e pobre em macronutrientes, especialmente fósforo, mas não em matéria orgânica em superfície.

\subsubsection{Gleissolos das Ipucas}

Esses perfis foram coletados em áreas florestais de Ipucas, obedecendo a uma toposseqüência desde as partes mais baixas (Gleissolo Melânico - P9), conhecidas como "funil", por onde escoa subterraneamente toda a água acumulada na cheia (Quadros 1 e 3). O Perfil P7 foi coletado na borda da Ipuca, sendo o solo desse ambiente caracterizado como Gleissolo Háplico, na transição para o Varjão. Os Gleissolos sob Ipucas são permanente ou periodicamente saturados de água, salvo se artificialmente drenados, o que conduz em geral ao desaparecimento das Ipucas. A água de saturação ou permanece estagnada internamente ou a saturação ocorre por fluxo subsuperficial lateral no solo (piping). Com o início das chuvas, a água do solo elevase por ascensão, atingindo a superfície (Figura 4).
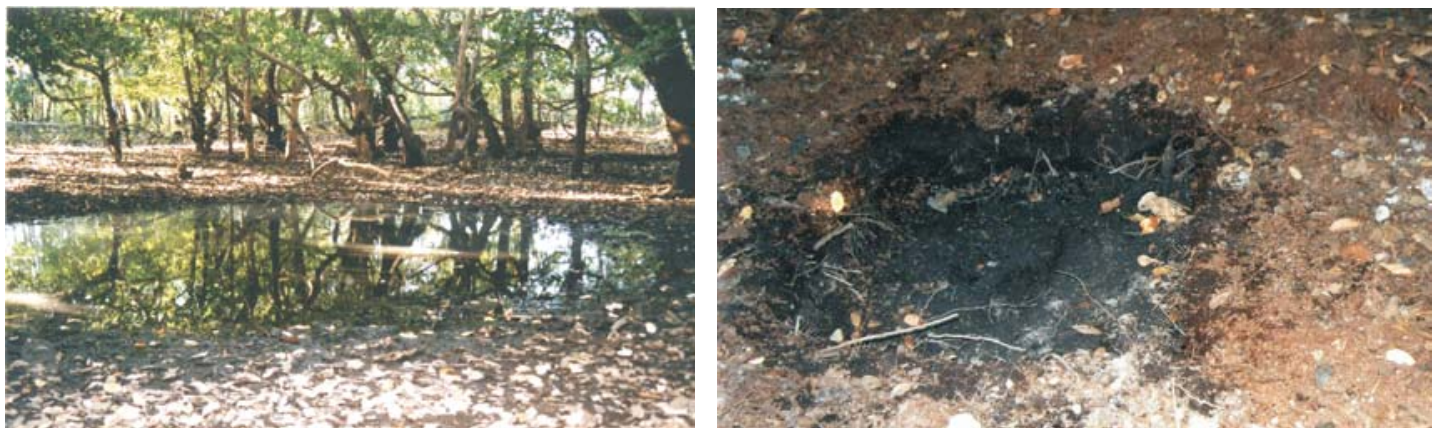

Figura 4 - Interior de uma Ipuca com água estagnada. Na imagem à direita, detalhe do setor conhecido como funil, originado pela dissolução de rochas calcárias (carste).

Figure 4 - The inside of an 'Ipuca' with standing water.

R. Árvore, Viçosa-MG, v.30, n.2, p.297-310, 2006

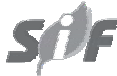


O Perfil 8 (Gleissolo Melânico), ilustrado a seguir, representa o solo do interior das Ipucas.

As Ipucas são fragmentos florestais de ocorrência natural e típica na depressão do Araguaia. Trata-se de uma floresta de natureza aluvial, sob um regime climático estacional com cinco a seis meses de seca, mas que permanece inundado no período chuvoso. $\mathrm{O}$ acúmulo de matéria orgânica no ecossistema de Ipucas resulta em materiais orgânicos extremamente ácidos e pobres em nutrientes, com horizontes gleizados com plintita em subsuperfície. No período final da estiagem, os solos hidromórficos encontram-se ressecados, com camadas de 20 a $30 \mathrm{~cm}$ de folhas secas, enquanto o lençol freático se situa entre 50 e $100 \mathrm{~cm}$ da superfície. O período de atividade microbiana é restrito a poucos meses do ano.

Essas formações florestais inundáveis, que ocupam as acumulações fluviais quaternárias, têm estrutura florística peculiar, aparecendo espécies vicariantes do Baixo Amazonas e dos rios Xingu e Araguaia. Assim, suas principais características florísticas variam de acordo com sua posição geográfica em que se insere a formação aluvial. A fitofisionomia das Ipucas aparece em forma de pequenas manchas circulares ou ovaladas em meio às paisagens da planície do Médio Araguaia.

Marimom e Lima (2001) realizaram estudos de caracterização fitofisionômica e florística em ambientes de Ipuca. Para esses autores, as Ipucas caracterizamse por apresentar diversidade florística baixa, ocorrendo em muitas áreas a dominância de uma única espécie, como Licania parvifolia. Dentre as espécies mais comuns, destacam-se a Acosmium nitens, Mabea pohliana, Panopsis rubescens e Sclerolobium froesii (MARIMON e LIMA, 2001).
Do centro das Ipucas para a borda, todos os solos são extremamente ácidos, com tendência de aumento de $\mathrm{P}$ disponível, acompanhado do aumento de carbono orgânico em superfície. Os teores de $\mathrm{Al}^{3+}$ são muito elevados, conferindo caráter alumínico em subsuperfície. Os teores de macronutrientes são muito baixos, o que corrobora a generalizada pobreza e distrofia da planície do Araguaia.

\subsection{Pedoambientes: Discussão Geral}

No Quadro 5 estão caracterizadas as unidades geoambientais da região, conforme os atributos pedológicos, geológicos, geomorfológicos e vegetacionais.

As Ipucas estão associadas aos solos mais ricos em matéria orgânica, possuindo aumento da fração areia para o varjão limpo, e a borda da Ipuca mais argilosa, ao gradiente textural. Em superfície, os solos variam de franco-arenosos no varjão limpo, até franco-argiloarenosos na borda da Ipuca. Verificou-se uma tendência de incremento de argila e matéria orgânica do varjão inundável com Plintossolos até as Ipucas com Gleissolo, em cotas mais baixas. Os solos do varjão foram classificados como Plintossolos Háplicos distróficos típicos (tanto no varjão sujo quanto no varjão limpo), embora nos murundus presentes no varjão, onde o aporte biológico promovido pelos térmitas se destaca, tinha-se uma podzolização evidente, com presença de Argissolo Acinzentado distrófico plíntico, desenvolvido sobre material argiloso trazido de subsuperfície. A maior densidade de vegetação do varjão sujo parece relacionarse aos teores de argila superiores aos do varjão limpo.

Quadro 5 - Geoambientes da depressão do Araguaia e suas características mais importantes

Table 5 - Geoenvironments of the Araguaia depression and its most important characteristics

\begin{tabular}{|c|c|c|c|c|}
\hline $\begin{array}{c}\text { Unidades } \\
\text { Geoambientais } \\
\end{array}$ & Substrato & Solos & Relevo & Vegetação \\
\hline Ipucas & $\begin{array}{c}\text { Material de acumulação } \\
\text { orgânica recente }\end{array}$ & Gleissolos & Plano & Floresta \\
\hline Varjão Limpo & $\begin{array}{l}\text { Área de acumulação } \\
\text { quaternária }\end{array}$ & Plintossolos & Plano & Campo Limpo \\
\hline Varjão Sujo & $\begin{array}{c}\text { Área de acumulação } \\
\text { quaternária }\end{array}$ & $\begin{array}{c}\text { Plintossolos e Argissolos } \\
\text { Acinzentados }\end{array}$ & Plano & $\begin{array}{c}\text { Campo Sujo } \\
\text { (Campo de Murundus) }\end{array}$ \\
\hline Cristas calcárias & $\begin{array}{l}\text { Calcários do Grupo } \\
\text { Tocantins }\end{array}$ & $\begin{array}{c}\text { Cambissolos e Neossolos } \\
\text { Litólicos }\end{array}$ & Ondulado & Mata Seca \\
\hline $\begin{array}{l}\text { Patamares } \\
\text { laterizados do } \\
\text { Médio Araguaia }\end{array}$ & $\begin{array}{l}\text { Couraça Laterítica } \\
\text { do Pleistoceno }\end{array}$ & $\begin{array}{c}\text { Cambissolos e } \\
\text { Plintossolos Pétricos }\end{array}$ & $\begin{array}{c}\text { Suave } \\
\text { ondulado }\end{array}$ & Cerrado \\
\hline $\begin{array}{l}\text { Níveis colinosos } \\
\text { com cerrados }\end{array}$ & $\begin{array}{l}\text { Saprolitos do } \\
\text { Grupo Tocantins }\end{array}$ & $\begin{array}{c}\text { Cambissolos e } \\
\text { Latossolos Plínticos }\end{array}$ & Suave ondulado & Cerrado \\
\hline Zonas ripárias & $\begin{array}{l}\text { Sedimentos fluviais } \\
\text { recentes }\end{array}$ & $\begin{array}{c}\text { Gleissolos e Neossolos } \\
\text { Flúvicos } \\
\end{array}$ & Plano & Floresta Ripária \\
\hline
\end{tabular}

R. Árvore, Viçosa-MG, v.30, n.2, p.297-310, 2006 
Os Gleissolos sob Ipucas (P8 e P9) são todos ácidos, com altos teores de alumínio, apresentando até mesmo caráter alumínico na parte mais baixa da seqüência (Gleissolo Melânico, P9). São solos extremamente pobres em nutrientes como cálcio, magnésio e potássio. $\mathrm{O}$ hidromorfismo deixa registrada a presença de horizontes gleizados, com ocorrência ou não de horizonte plíntico.

Os solos de varjão, em função do acúmulo de matéria orgânica, são menos pobres quimicamente, com teores de cálcio, magnésio e especialmente fósforo um pouco superiores. Boa parte dos nutrientes está ligada à fração humificada, condicionando maior CTC. Os teores de carbono superficiais nas Ipucas são elevados, variando de 66,2 a $117,1 \mathrm{~g} \mathrm{~kg}^{-1}$ nos horizontes A, caracterizando horizontes melanizados no caso do perfil P8, embora sem possuir profundidade suficiente para caracterizar um Organossolo. Os teores de P são maiores no centro que na borda da Ipuca. Os teores de alumínio trocável são bem mais elevados nos solos de Ipucas, mas grande parte está associada à matéria orgânica, sendo menos fitotóxicos.

As características dos solos das Ipucas, observadas nos levantamentos existentes, ilustram seu hidromorfismo, com influência do lençol freático próximo à superfície. As camadas superficiais, principalmente no interior do fragmento florestal, são ricas em matéria orgânica de natureza ácida.

Os resultados da análise granulométrica revelaram que os eventos responsáveis pela deposição das camadas sedimentares são comandados por ciclos de inundação com energia e distâncias variáveis (demonstrada pela alternância de materiais finos, silte e argila). Os sedimentos aprisionados nas depressões do terreno criam mecanismo de recarga hídrica subterrânea através de fluxos laterais ou subsuperficie. Esse processo é relacionado com as enchentes e vazantes anuais.

\subsection{Modelo de evolução dos solos e das Ipucas}

O rebaixamento do lençol freático por causas naturais resulta em erosão e colapso, por meio dos seguintes processos:

- Ferrólise e destruição de argilas em ambientes sazonalmente hidromórficos (BRINKMAN, 1970; ANDRADE et al., 1997).

- Dissolução de terrenos carbonáticos em subsuperfície e formação de depressões de dolinas (cársticas) (THOMAS, 1994).

- Subsidência de turfeiras pela drenagem excessiva (THOMAS, 1994).

Os processos de destruição de argilas foram descritos por Brinkman (1970), Chauvel (1977) e Aleva (1991). Ambientes planos e hidromórficos, à semelhança do Médio Araguaia, onde ocorre ferrólise, apresentam uma redução em volume de solo de até $30 \%$, contribuindo para o rebaixamento localizado das superfícies inundadas, formando áreas aluviais internas (Hollows) mais rebaixadas, onde se desenvolvem as Ipucas e solos orgânicos ácidos. Na borda da depressão do Araguaia, tal formação pode ainda ser facilitada pela existência de substratos carbonáticos em subsuperfície, acelerando a remoção subsuperficial dos produtos solúveis.

Os mecanismos de ferrólise, em alternância de substratos arenosos e argilosos, além da possível presença de carste em profundidade, podem, assim, explicar a atual tendência ao colapso de Ipucas em áreas onde houve o rebaixamento artificial da drenagem, acelerando os mecanismos de remoção subsuperficial, como pode ser observado na Figura 5.

Outro aspecto a se considerar é a subsidência das Ipucas por drenagem artificial e excessiva dos solos, induzindo a mineralização de matéria orgânica, rebaixamento do lençol freático e colapso do solo. Todos os fatores anteriormente mencionados podem atuar simultaneamente na área de ocorrência de Ipucas.

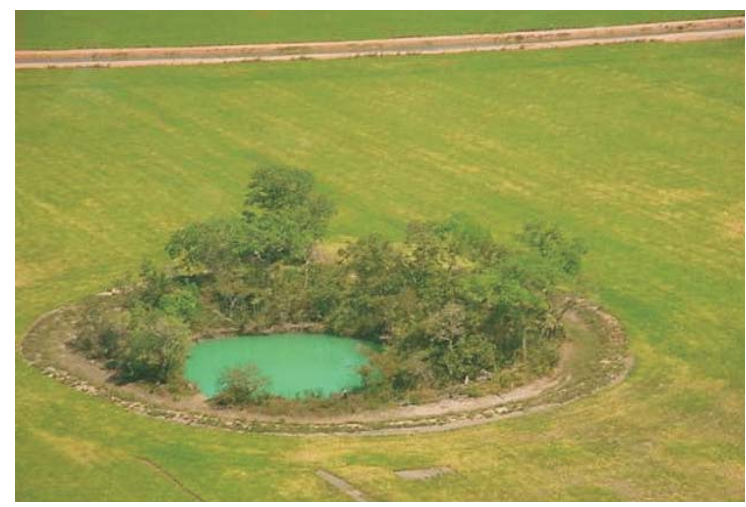

Figura 5 - Dolina em área de cultivo de arroz, formada pela subsidência recente (colapso) de uma Ipuca.

Figure 5 -A sinkhole in rice crop area, formed by the recent collapse of an 'Iриса'. 


\section{CONCLUSÕES}

- Em ambientes de Ipucas, boa parte dos nutrientes, especialmente $\mathrm{P}$, está concentrada ou ligada à fração humificada.

- Os teores de Al trocáveis são bem mais elevados nos solos de Ipucas e estão associados à matéria orgânica. Os Gleissolos Melânicos característicos do ambiente interno das Ipucas possuem elevados teores de carbono superficiais.

- O hidromorfismo do ambiente de Ipucas se evidencia pela presença de horizontes gleizados, com ocorrência de mosqueados. Comparados aos solos do varjão, fora das Ipucas, os Gleissolos de Ipucas são menos pobres quimicamente, com maiores teores de $\mathrm{Ca}, \mathrm{Mg}$ e, especialmente, $\mathrm{P}$, ainda que sejam ácidos e de baixa CTC.

- Mecanismos de destruição de argilas, com alternância de substratos arenosos e argilosos, além da possível presença de carste em profundidade, podem explicar a atual tendência ao colapso de Ipucas em áreas onde houve o rebaixamento artificial da drenagem, acelerando os mecanismos de remoção subsuperficial.

- As Ipucas são Florestas Hidrófilas e Higrófilas, o que impõe a necessidade de incluí-las na categoria de área de preservação permanente.

\section{REFERÊNCIAS BIBLIOGRÁFICAS}

ALEVA, G. J. J. Tropical weathering, denudation and mineral accumulation. Geologie en Mijnbouw, v. 70, n.1, p.35-38, 1991.

ANDRADE, H. et al. Pedogeomorfologia e micropedologia de uma seqüência latossolo-area quartzosa hidromórfica sobre rochas cristalinas no Estado do Amazonas. Geonomos, v. 5, n.3, p.55-66, 1997.

ARAÚJO NETO, M. D. et al. The murundus of the Cerrado region of Central Brazil. Journal of Tropical Ecology, v. 2, p. 17-35, 1986.

AZOLIN, M. A. D.; KLANT, E.; SANTOS, M. C. C. Relações solo-superfícies geomórficas e material de origem a oeste da depressão central e campanha no Rio Grande do Sul. In: CONGRESSO BRASILEIRO DE CIÊNCIA DO SOLO, 15., 1975, Campinas. Anais... Campinas: SBCS, 1976. p. 345-350.
BERG, M. V.; LEPSCH, I. F.; SAKAI, E. Solos de planície aluviais do vale do Ribeira do Iguape: I Padrões de distribuição. Revista Brasileira de Ciência do Solo, v. 11, p. 305-317, 1987.

BRASIL. Ministério das Minas e Energia. Secretaria Geral. Projeto

RADAMBRASIL. Folha SC. 22.

Tocantins: Geologia, geomorfologia, pedologia, vegetação e uso potencial da terra. Rio de Janeiro: 1981. 524 p.

BRASIL. Ministério do Meio Ambiente e da Amazônia Legal. Instituto Brasileiro do Meio Ambiente e dos Recursos Naturais Renováveis - IBAMA. Plano de Ação Emergencial para o Parque Nacional do Araguaia. Brasília: 1994. 56 p. (Documento de informações básicas).

BRINKMAN, R. Ferrolysis, a hidromorphic soil forming process. Geoderma, v. 3, n.3, p. 199-206, 1970.

CHAUVEL, A. Recherches sur la transformation des sols ferrallitiques dans la zone tropicale à saisons contrastèes. Travaux et Documents de L'ORSTOM, v. 62, p. 532-548, 1977.

COMPANHIA DE DESENVOLVIMENTO DO ESTADO DO TOCANTINS - CODETINS. Estudo de Impacto Ambiental EIARIMA, Projeto Javaés: sub-projeto Lagoa. Palmas: 1996. 2v.

CORRÊA, G. F. Les microrelief "murundus" et leur environnement pédologique dans l'ouest du Minas Gerais, région du plateau central brésilien. 1989. 144f. Thèse (Doctorat em Seul) - Université de Nancy I, Vandoeuvre-lesNancy, 1989.

\section{CENTRO TECNOLÓGICO DE ENGENHARIA -} CPT. Projeto Javaés - Subprojeto Xavantes: EIA/RIMA. Diagnóstico Ambiental do Meio Biótico. Palmas: CPT, 2002. p. 1-110.

DANIELS, R. B.; GAMBLE, E. F.; CADY, J. G. The relation between geomorphology and soil morphology and genesis. Advances in Agronomy, v. 23, p. 51-87, 1971.

R. Árvore, Viçosa-MG, v.30, n.2, p.297-310, 2006 
DENNISTON, D. Sustainning Mountain peoples and environments. In: LINDA S., (Ed.).

The state of the world. New York: WW Norton \& Company, 1995. p.38-57.

EMPRESA BRASILEIRA DE PESQUISA AGROPECUÁRIA - EMBRAPA. Centro Nacional de Pesquisa de Solos. Rio de Janeiro. Sistema brasileiro de classificação de solos. Brasília: 1999. 412 p.

FELFILI, J. M. Principais fisionomias do Espigão Mestre do São Francisco. In: FELFILI, J. M.; SILVA JUNIOR, M.C. (Org.). Biogeografia do Bioma Cerrado: Estudo fitofisionômico na Chapada do Espigão Mestre do São Francisco. Brasília: Universidade de Brasília, 2001. p. 18-30.

HAYES, M. H. B. et al. The search for structure:setting the scene. In: HAYES, M. H. B. et al. Humic substances II, In search of structure. Chichester: John Wiley \& Sons, 1989. p.4-30.

LEMOS, R. C.; SANTOS, R. D. Manual de descrição e coleta de solo no campo. 2.ed. Campinas: SBCS/SNLCS, 1984. 45p.

LEPSCH, I. F. Superfícies geomorfológicas e depósitos superficiais neocenozóicos em Echaporã, SP. Boletim Paulista de Geografia, v. 53, p. 5-34, 1977.

LOBO, A. E. M. Relações solos-superfícies fisiográficas em uma transição de Piracicaba, SP. 1984. 164f. Tese (Doutorado em Agronomia) - Escola Superior de Agricultura "Luiz de Queiroz", Piracicaba, 1984.

MARIMON, B. S.; LIMA, E. S. Caracterização fitofisionômica e levantamento florístico preliminar no Pantanal dos Rios Mortes-Araguaia,

Cocalinho, Mato Grosso, Brasil. Acta Botânica Brasileira, v. 15, n. 2, p. 213-229, 2001.

MARTINS, I. C. M. et al. Diagnóstico ambiental no contexto da paisagem de fragmentos florestais naturais "ipucas" - no Município de Lagoa da Confusão-Tocantins. Revista Árvore, v. 26, n. 3, p. 299-309, 2002.

McKEAGUE, J. A.; DAY, J. H. Dithionite and oxalate-extractable Fe and AI as aids in diferentiating various classes of soils. Canadian Journal Soil Science,v.46, p. 13-22, 1966.

R. Árvore, Viçosa-MG, v.30, n.2, p.297-310, 2006
MEHRA, J. P.; JACKSON, M. L. Iron oxides removal from soils and clays by a dithionitecitrate-bicarbonate system buffered with sodium bicarbonate. Clays Clay Minerals, v.7, p. 317-327, 1960.

MUNSELL. Soil color charts. Baltimore: Munsell Color Company, 1994. 28p.

ONA S.A. Engenharia, Comércio e Industria. Projeto Rio Formoso: Suplementação dos Recursos Hídricos, 2001. v.1.219p, (Relatório Técnico).

RESENDE, M. et al. Pedologia: base para distinção de ambientes. 4.ed. Viçosa, MG: Editora UFV, 2002. 338 p.

RIBEIRO, A.C.; GUIMARAES, P.T.G.; ALVAREZ V., V.H. (Ed.). Recomendação para o uso de corretivos e fertilizantes em Minas Gerais: 5. Aproximação. Viçosa, MG: Comissão de Fertilidade do Solo do Estado de Minas Gerais, 1999. 359p.

RIBEIRO, J. F.; WALTER, B. M. T.

Fitofisionomias do bioma do cerrado: os biomas do Brasil. In: Cerrado: ambiente e flora. Planaltina, DF: Embrapa, 1998. p. 89-116.

RIZZINI, C. T. Árvores e madeiras úteis do Brasil: manual de dendrologia brasileira. São Paulo: Edgard Blucher, 1992. 295 p.

RODRIGUES, T. E.; KLANT, E. Mineralogia e gênese de uma seqüência de solos do Distrito Federal. Revista Brasileira de Ciência dos Solos, v. 2, p. 124-132, 1978

YEOMANS, J. C.; BREMNER, J. M. A rapid and precise method for routine determination of organic carbon in soil. Communication in Soil Science Plant Analisys, v.19, p.1467-1476, 1988.

SILVA JUNIOR, M. C.; FELFILI, J. M. A vegetação da Estação Ecológica de Águas Emendadas. Brasília-DF: GDF SEMATEC/IBAMA, 1996. v.1, 35p.

THOMAS, M. F. Geomorphology in the Tropics: a study of weathering and denudation in low latitudes. New York: Other Wiley Editorial Offices, 1996. 460p. 